\title{
The Organization of Words in Mental Lexicon: Evidence from Word Association Test
}

\author{
Budi Eko Pranoto ${ }^{1}$, Lidia K. Afrilita ${ }^{2}$ \\ budi.epranoto@gmail.com ${ }^{1}$, lidiaafrilita@yahoo.com ${ }^{2}$ \\ Universitas Teknokrat Indonesia ${ }^{1}$ \\ Universitas Indonesia ${ }^{2}$
}

\begin{abstract}
Both in psychology and linguistics studies, memory is one of the core of interests amongst researchers. In linguistics, memory is the place where language processes consisting of language perception, storage, and access of words take place. Words, in memory, are stored in complex, clear, well-organized, and ordered networks called nodes, which can be represented by World Wide Web. This word organization in psycholinguistics is referred to mental lexicon. This study aims to investigate what kind of nodes representation stored in mental lexicon of foreign language learners. Word Association Test (WAT), the well-known study method in both psychology and linguistics studies, is employed by using English Swadesh word list as the stimulus to elicit the lexical relation amongst words. The basic principle of the test is giving a stimulus to respondents and asking them to give the very first word coming out of their mind. Respondents are undergraduate students of English Literature a university in Indonesia. Findings of this research support the previous findings stating that non-native speakers tend to make syntagmatic relation, which is mostly dominated by collocation association. Interestingly, the finding also shows that the words network in mental lexicon involves a dynamic development based on experience and perception of the respondents.
\end{abstract}

Key Words: lexical relation, mental lexicon, word association

\section{Introduction}

Research on conceptual models and lexical relations has become prominent part of the development of psycholinguistics and interdisciplinary research since the 1960s (Steinberg, 2002: 108). Research on lexical relations rooted from research in the field of semantic studies which aim to find the tendency of someone to give definition of a word. In semantic studies, one of the approaches that can explain the meaning of a word is linguistic approach performed by using lexical relations strategies, which include synonymy, antonym, meronymy, or hyponymy relations (Riemer, 2005).

In psycholinguistics, lexical relations can be a method to see how the mental lexicon model network is structured within a person's cognition. Peppard (2007: 2) makes metaphors of mental lexicon like dictionary, thesaurus, encyclopedia, library, computer, and network. Even Brown in Peppard (2007: 2) adds a more modern metaphor by comparing the mental lexicon with the World Wide Web. This means that mental lexicon is not simply formed, but arranged in such order with clear groupings, traceable network, but dynamic and can evolve at any time. Like World Wide Web, mental lexicon is formed through three processes that occur continuously in the cognition, starting from the input process, storage, and retrieval. A new received word will be perceived into mental lexicon and then be incorporated into the appropriate category based on a new word connection with other words that have been stored in the mental lexicon. If the connection between the new word and the pre-existing words is close enough, the new word will be stored in the long-term memory. Organization of words stored in our permanent memory is called internal lexicon or mental lexicon (Carroll, 2008: 103).

According to Aitchison (1994) there are four main methods to study the internal lexicon, through (1) research on tip of the tongue and slip of the tongue; (2) linguistic and corpus linguistic; (3) speech disorder and brain scans; and (4) psycholinguistic experiments. The focus of this research is on the storage process, so one of the psycholinguistic studies that can be applied to research the lexical storage network model inside the internal lexicon is Word Association Test.

If someone hears or reads the word 'doctor' and the next words likely to appear in a person's cognition are 'nurse', 'hospital', or 'patient'. The connection of the word 'doctor' to other words that being activated when the word 'doctor' is caught by the senses is called word association. The word association test is performed by giving a oneword stimulus to the participants, then they are asked to write or mention the first word that comes to mind when they hear or read the word. In addition, the word association test can also be done by priming method, which is to 
provide word interference that related or not related to the stimulus. Many previous studies have proved that the associated word tends to be accessible more quickly by respondents.

Another issue related to word association that caught more attention is its relation with foreign language learning (L2). The word association research on bilingual speakers aims to look at the relationship between mental lexicon in L1 and L2. In addition, this research method is also used as an indication of lexical development or language proficiency in foreign language learners (Roex, 2013). Therefore, the results of research by word association method can also contribute in foreign languages teaching (Peppard, 2007), (Meara, 1983), Menenti (2006), and Sheng, et.al (2006).

\section{Theory and Method}

\section{Types of Words Association}

The connection among words can be analyzed by using two basic principles of word association, namely syntagmatic and paradigmatic (Coulthard et al., 2006; Meara, 1982 in Menenti (2006)). In many other literatures, a third principle is added, i.e. word associations based on phonological or orthographic relations (Peppard, 2007). Wolter (2001) also makes the same classification as above, but he refers to the term phonological relation as 'clang', i.e. words that have sound resemblances, but have no semantic relation to each other.

The Syntagmatic Association is a textual relation that can be analyzed by looking at words that appear before or after the stimulus word. For example, when given a stimulus 'solar', respondents provide syntagmatic associations, 'sunrise' 'morning', or 'sunset'. Syntagmatic relations can form sequence relationships and construct a grammatical order. One of syntagmatic relations is collocation (Peppard, 2007). Collocation is the commonly emerging words or called as word network (Aitchison, 1994: 84). Collocation has a particular pattern based on grammatical and lexical, for example the word 'beautiful' is collocated with 'female', 'woman' or 'girl', while the word 'handsome' is collocated with 'male'. McCarthy (1990) adds an encyclopedic classification of meaning relations; a knowledge of words in relation to referents or specific contexts in the real world. This knowledge does not connect the semantic relation or phonological relation between two words, but the relationship is subjective based on specific experiences or cultural background, such as the word 'my husband' in response to the word 'love'. This encyclopedic relation belongs to the syntagmatic association because it can form a grammatical sequence construction as well as collocation.

The paradigmatic association refers to words that belong to the same word class as the stimulus and can substitute, for example, for the word 'eat', the paradigmatic relationships that may arise are 'cooking' and 'buying'. The main criterion for the paradigmatic association category is the response word should have a semantic relationship with the stimulus. Included in this category are coordination, meronymy, taxonomy, and synonym relations (Cruse, 2004). Coordination relations are word relations that belong to the same word class, for example the words 'cat' and 'dog' have coordination relationships because they are both under the category of animals (Carroll, 2008: 106). Aitchison mentions that this relation is the most common relation produced by native speakers (2003: 80). Taxonomy is a super ordinate relation to its subordinate in a hierarchy, for example, sparrows and pigeons are hyponym of birds. Meronymy is the relationship between the part of an object and the whole object, for example the word 'machine' is a meronymy of 'car', or 'table leg' as a meronymy of the word 'table'. A synonymy relationship is a word relation that has same meaning. Although there are no absolute synonyms, in most cases, two synonymous words can be substituted in some contexts (Cruse, 2004). The last, antonym relationship is relation that shows contrasting relationships, such as young and old.

Phonological relation or clang is a semantic relation based on sound or orthographically similar. Aitchison (1994) describes it as a bath up effect to explain one's tendency that easier to remember the beginning and end of the word; for example, first $\square$ fast; finally $\square$ formal (Fay and Cutler in Peppard, 2007).

\section{Previous research}

Research on large scale word association tests was first performed by Kent and Rosanoff in Carroll (2008). They read out one by one the words that were taken as stimulus. Research respondents were then asked to give the first word other than the stimulus, which popped into their minds shortly after listening to the stimulus. A study of 1000 male and female respondents from various educational and occupational backgrounds found four prominent semantic types of relationships: (1) taxonomic relation, such as furniture as hypernym, tables and chairs as hyponym of furniture; (2) meronymy relation, such as chairs, seat cushions, and chair legs; (3) attributive relation, usually an adjective describing the stimulus, such as wood, round, brown; and (4) functional relation, such as chair $\square$ sit, rest, lean. 
A word association test conducted on respondents with speech disorder found that the dominant lexical relationships are coordination, collocation, super ordinate and synonymy. In addition, the study also concluded that coordination is the most common type of lexical relation found in L1 speakers, followed by collocation relations (Aitchison, 1994). The study also found that from the responses given by the respondents, the frequency of responses based on phonological or clang relations are rare. This indicates that the association of lexicon meaning is stronger than sound similarity or written form. The word association research on bilingual was also performed by Meara (1978) through the Birkbeck Vocabulary Project. The results of this study indicate that the percentage of paradigmatic relations on L1 is greater than L2, whereas the percentage of syntagmatic relation response is found higher in L2.

The previous studies of word association tests also show that paradigmatic associations are the dominant association of native speakers, whereas syntagmatic associations are dominant in foreign language learners (Meara, 1982). Fitzpatrick (2007) who examines the mental development of the lexicons of English native speakers and English learners as L2 found that the word association response in adults tends to be homogeneous. The association pattern of L2 is different from the association pattern of L1, and lexical development in L2 will follow the lexical development pattern of native speakers; starting from the phonological, syntagmatic, to paradigmatic relationships in language speakers with advanced proficiency level.

\section{Methodology}

Methodology is a very important part of experimental psycholinguistic research to understand the processing of language in a person's cognition. Cowles (2011: 38) mentioned a good research methodology will be the right tool for the right job, making it easier for researchers to reduce the arguments that can weaken the results of his research. Cowles (2011: 37:52) describes that experimental psycholinguistic research techniques are broadly divided into two types, namely online and offline. The research technique that will be used is the offline method by using the research questionnaire.

Participants: Participants consisted of 15 students of S1 English Literature at Faculty of Humanities, Universitas Indonesia. Participants are learners of English as a foreign language.

Instruments: The instruments used in this word association test are 45 basic words taken from Swadesh (English version). The use of the Swadesh wordlist as a stimulus aims to ensure that the concepts and references raised by a word are the same. The stimulus words are divided into different word classes based on the distribution of Bowern (2007), but for the purposes of this study, only the class words of adjective, verbs, and nouns are taken. Each word class consists of 15 words. The list of stimulus words can be seen in Appendix A.

Procedure: This study is conducted by giving a research questionnaire containing 45 words of stimulus to 15 respondents who are English learners at Faculty of Humanities, Universitas Indonesia. After the questionnaires are given, respondents are given 5 seconds to respond for each word of stimulus.

Data analysis technique: From the research questionnaire that has been filled by the respondent, the researcher groups the data individually based on eight types of meaning relation, namely collocation, encyclopedic, coordination, meronymy, taxonomy, antonym, synonym, and clang. Furthermore, the frequency of occurrence of each relation based on the adjective word adjectives, verbs, and nouns are then calculated. Words whose relation does not belong to the eight categories of meaning relations are included in the 'other' category to then be analyzed the relationship between the stimulus and response.

\section{Findings and Discussion}

\section{Description of Data}

The following is the data descriptions based on the relations of meaning.

\begin{tabular}{|c|c|c|c|c|c|c|c|c|c|c|}
\hline \multirow{2}{*}{ No } & \multirow{2}{*}{$\begin{array}{l}\text { Word } \\
\text { class }\end{array}$} & \multicolumn{2}{|c|}{ Syntagmatic } & \multicolumn{5}{|c|}{ Paradigmatic } & \multirow{2}{*}{ Clang } & \multirow{2}{*}{ Other } \\
\hline & & Collocation & Encyclopedic & Coordination & Meronymy & Taxonomy & Antonym & Synonym & & \\
\hline 1 & Adjective & 188 & 9 & 4 & 0 & 4 & 1 & 12 & 1 & 2 \\
\hline 2 & Verb & 133 & 4 & 8 & 7 & 2 & 4 & 22 & 0 & 5 \\
\hline 3 & Noun & 161 & 5 & 10 & 26 & 17 & 1 & 0 & 2 & 0 \\
\hline \multicolumn{2}{|c|}{ Percentage } & \multicolumn{2}{|c|}{$79.5 \%$} & \multicolumn{5}{|c|}{$19 \%$} & $0.5 \%$ & $1 \%$ \\
\hline
\end{tabular}

Based on the above table, the syntagmatic relation dominates the distribution of data with a percentage of $79.5 \%$ of the total data that has been collected. Syntagmatic relations are textual relations that can be analyzed by looking at words that appear before or after the stimulus (Meara, 1982). In this study, the syntagmatic relation 
consists of collocation and encyclopedic. Of the two types of relations, collocation shows a very high number with an average of 160 occurrences in each category of stimulus. Meanwhile, encyclopedic relationships do not show significant differences if compared with other types of relationships. From the number of data findings, the collocation relation on each type of stimulus is as follows: adjectives are 188 words (39\%), verbs are 133 words (27.6\%), and nouns are 161 words (33.4\%). The encyclopedic relation is a type of relation that can be considered to have subjective characteristics because it is derived from the knowledge of the word in relation to a referent or a specific context in the real world (McCarthy, 1990). From the above data findings, in each stimulus category there is an emergence of encyclopedic relations as follows; adjectives ( 9 words, 50\%), verbs (4 words, 22\%), and nouns (5 words, $33 \%$ ).

The next type of relation is a paradigmatic relation, a relation that refers to words that belong to the same word class as the stimulus and can be interchangeable (Meara, 1982). There are five types of relationships in the paradigmatic association group, i.e. coordination, meronymy, taxonomy, antonym, and synonym that have an accumulated appearance of $19 \%$ of the total data. In the noun word class, the quite high response is the coordination relationship (45.5\%), meronymy (79\%), and taxonomy (73.9\%). In the meantime, the adjective verb and verb classes show varying occurrences, ranging from 2 to 8 occurrences, except for the types of meronymy relations that did not appear in the adjective word class. Furthermore, the type of antonym relation has the number of occurrences of 6 words of the three word classes, i.e. 1 word on adjectives, 4 words in verbs, and 1 word in nouns. The last type of relation on a paradigmatic umbrella is a synonym, which occurs as many as 12 words (35.3\%) in adjectives and 22 words $(64.7 \%)$ in verbs.

The last two relationships are clang and others whose numbers are relatively small compared to other types of relationships. The relation of Clang only appears in 3 words $(0.5 \%)$, i.e. 1 word in the adjective word class and 2 words in the noun. Based on the findings of this study, the type of "other" relation indicates the derivation form of the stimulus. Overall, the percentage of occurrences is $1 \%$ with 2 occurrences on adjectives and 5 words in verbs.

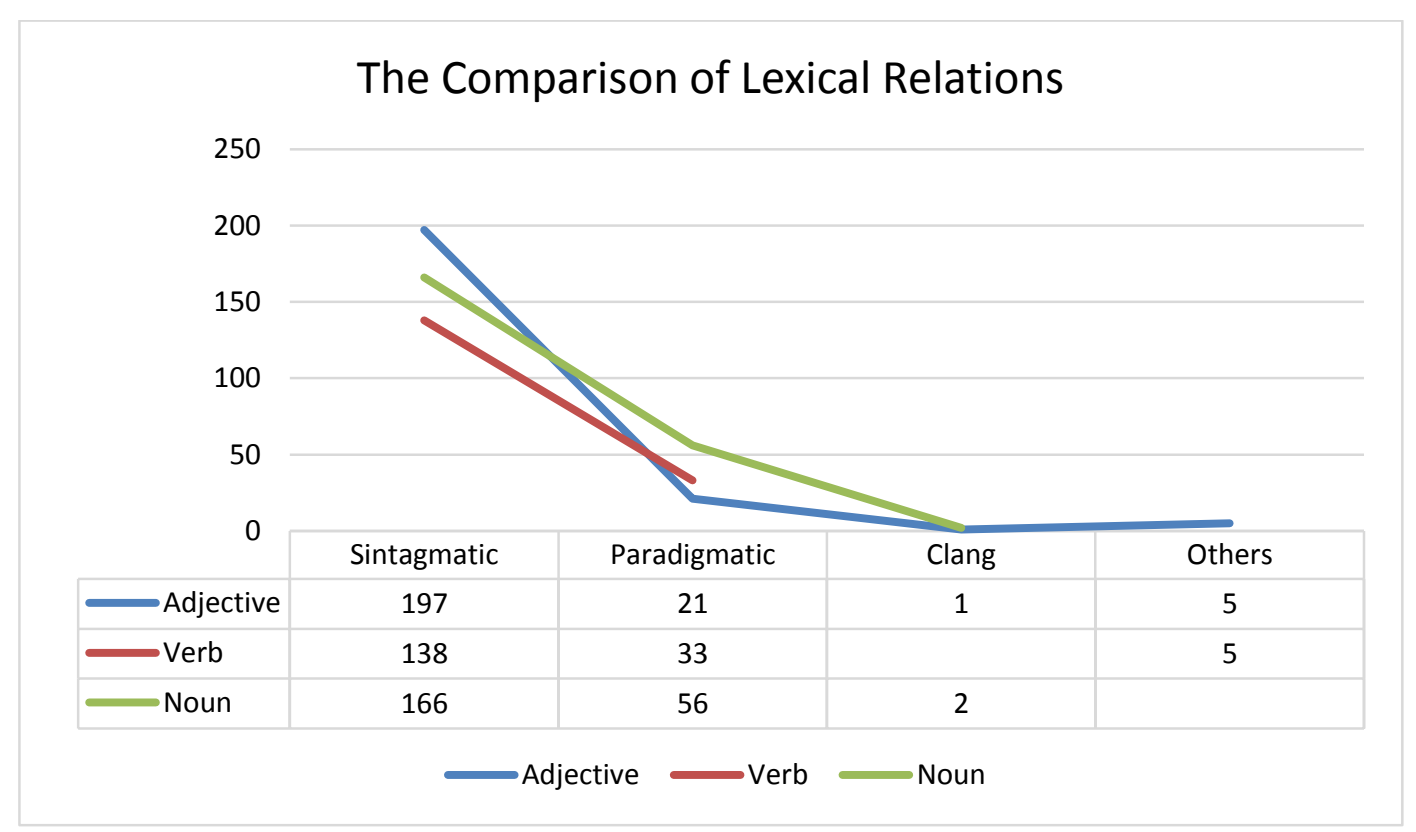

The above comparison table shows that the relation to the adjective appears in all types of relations discussed in this research, followed by the higher frequency of nouns on paradigmatic relations. Mean while, the relations to verbs appear only in syntagmatic and paradigmatic sections.

\section{Pattern of Language Learners' Mental Lexicon}

The word association test is one of the experimental methods in psycholinguistics that can be used to see how the pattern of organizing words in the mental lexicon of a language speaker. Fitzpatrick (2000) and Meara (1982) suggest that the pattern of lexical relationships between native speakers and foreign language learners is generally different and the word association test data is one of the methods for knowing the difference.

The lexical relation pattern of this test can also provide an overview of the lexical access mechanism of the language speakers. Carroll (2008: 118) states that there are several variables that affect lexical access, among which 
are phonological and semantic variables. Words that have similar sound resemblances and words that have strong semantic relationships will be faster and more accessible than words with weak phonological or semantic relationships. Based on the basic principles of word association tests, the first response that appears indicates that the word has the strongest network or connection with the stimulus. Based on this, the findings of this research can illustrate the organizational map of words in the mental lexicon of an English learner.

The descriptions of the above data show that the most dominant lexical relationships appear are syntagmatic associations. The findings of this research are consistent with the findings of previous studies (Meara, 1982) which suggest that foreign language learners tend to respond syntagmatically toward the stimulus, e.g. responses to adjective word big are noun building, dream, elephant, boy, dinosaur, universe, world, and ball; the responses to the stimulus eat are nouns (rice, pasta, food, lunch, noodle, eat, meat) and adjectives (hungry and delicious). This finding indicates that the strongest lexical network in the respondent's mental lexicon is a syntagmatic network, especially collocation relations. The following are examples of networks that are formed in the mental lexicon of respondents toward the word sharp.

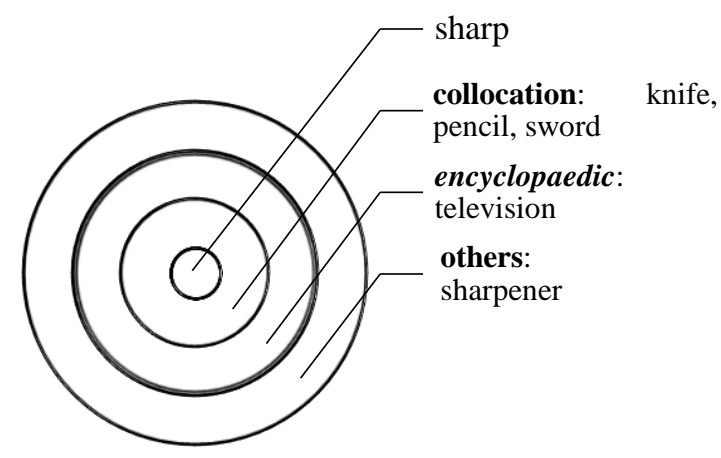

Respondents make syntagmatic lexical access through collocation relations by accessing the words knife, pencil, and sword from within their mental lexicon. The words associated with the word sharp, such as knife, pencil, and sword are considered to have a sharp surface and conform to definition of sharp. The following relation that emerges is an encyclopedic relation that is considered to have a subjective character because it derives from the knowledge of the word in relation to a referent or a specific context in the real world (McCarthy, 1990). Respondents access the word television from within their mental lexicon in response to the word sharp. This finding becomes very interesting because a television does not have a sharp surface that can be attributed to the meaning of the word sharp. However, the word sharp by the respondent is considered as one of the brands of electronics manufacturers from Japan who have entered the electronic market in Indonesia and has often seen in everyday environment. This finding becomes a proof that a person's mental lexicon is not static, but dynamic. The mental lexicon develops according to the events experienced by the language learner. Thus, it can be assumed that if there is no electronic manufacturer called Sharp, the word television will not appear. The next relation type is "other" relation which after being examined refers to the derivation form of the stimulus. From the word sharp, respondents access the word sharpener from within their mental lexicon. The word sharpener is a derivation of the word sharp.

Words organization map in the English learners mental lexicon of verbs (used as a stimulus) can be seen below. The word give is given as a stimulus. The result is presented in three circles below. The circles illustrate the location as well as indicate the distance of access in the speaker's mental lexicon. 


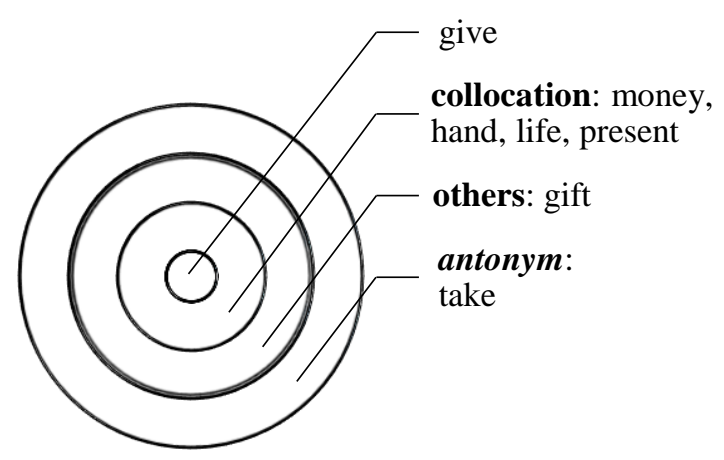

Similar with the word class of adjectives, the first access process by respondents is a syntagmatic relation through a collocation form. Respondents access the word money, hand, life, and present from within the mental lexicon. The words lie closest to the stimulus, followed by the word gift as a derivation form of the word give. The accessing process through collocation form also re-confirmed previous research which states that foreign language learners tend to use syntagmatic access, rather than paradigmatic.

However, in the above map can be seen also antonym relation performed by respondents in accessing words in their mental lexicon. Based on Carroll's (2007) opinion, antonym is part of a paradigmatic relationship. On the map above, the respondents accessing the word take which is the antonym of the stimulus. However, the location of the word is in third layer of circle outside the stimulus. This shows the distance of the access in a person's mental lexicon. In addition, paradigmatic relation is a distinct lexical access performed by native speaker of a language. In this research, respondents are foreign language learners, so the production of paradigmatic relations tends to be small.

Slightly different from the organization map in the mental lexicon of foreign language speakers in accessing the word class when the verb words are given as a stimulus, the noun stimulus has its own illustration. It can be seen in the map below, there are two rings that circling the stimulus. The two rings consist of a syntagmatic relation of "collocation" and a "taxonomy" paradigmatic relation.

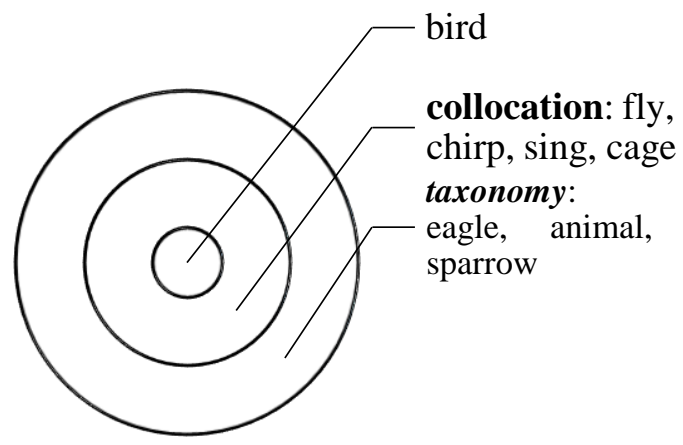

Like both adjectives and verbs, the response to the noun word is also accessed most quickly by syntagmatic association, i.e. collocation. Based on the above map, the fastest-accessed words from within the mental lexicon are the words fly, chirp, sing, and cage. Furthermore, paradigmatic access is done by taxonomy relation. The words accessed by respondents are the words eagle, animal, and sparrow. The above map also again shows that the common access by foreign language learners is syntagmatic.

\section{Dynamics of Mental Lexicon}

Aitchison (1994) states that the mental lexicon is dynamic and evolves with the perceptions received and events experienced by the learner. The findings of this study support this view. Some of the responses obtained in this research indicate that a word in the mental lexicon can continue to evolve and form a new network with new words, specific to a particular individual. The following is the data findings that support the above view. 


\begin{tabular}{|c|l|l|}
\hline No. & Stimulus & \\
\hline 1. & Sharp & Television \\
\hline 2. & \multirow{2}{*}{ Dry } & Fit \\
\cline { 3 - 3 } & & Depok \\
\hline 3. & \multirow{2}{*}{ Far } & Bekasi \\
\cline { 3 - 3 } & & My soul mate \\
\hline 4. & Bird & Twitter \\
\hline 5. & Small & Minion \\
\hline 6. & New & Balance \\
\hline 7. & Wide & Play station \\
\hline 8. & Woman & Red-dressed woman, Scarlett Johansen \\
\hline
\end{tabular}

The table above is the result of the findings in this research which is considered to be evidence that the form of referent in a person's mental lexicon is always in a dynamic state. The word sharp has no semantic or phonological relation with the word television. However, the use of the word sharp as a brand of one electronic product causes the respondent to build a new network for the word sharp. Also with stimulus dry and fit (response). Both have neither semantic nor phonological relations, but they are interconnected by a new concept formed by the concept of dry-fit, which is one of the technologies in Nike's sportswear production, which can absorb water well. Meanwhile, the word Bekasi appears in response to the word far. This finding is very interesting because it illustrates how issues that develop in the mass media can enrich the mental lexicon with new associations. These findings indicate that the referent in a person's mental lexicon is slowly influenced by the surrounding environment, whether in the form of natural conditions, social issues, technology, and economy. Words will evolve to form new networks, just like the World Wide Web on the internet (Peppard, 2007).

\section{Implication toward Language Teaching}

The main purpose of this study is to provide an overview of learners' mental lexicon of foreign language; so that it can be used as a reference to determine teaching methods that can help strengthen the network of words in the mental lexicon. The findings of previous research suggest that the development of words organization starts from the earliest stages, namely through phonological relations or clang in early-level language learners. Therefore, the association of the target word (L2) with other words in mother language (L1) can be used as a preliminary method to teach a new vocabulary to the early-level learner, for example to associate the word pancake to puncak, cunning to kuning.

The findings of this study also show that semantic network; especially syntagmatic is the dominant network in mental lexicon. This indicates that teaching vocabulary and its meanings is not enough to enrich the language learners' mental lexicon. In accordance Aitchison (1994) who states that words are stored in network form, any new words that enter into the mental lexicon cannot be isolated on their own, but rather need to determine its position in the existing network, or form a new network. Therefore, in accordance with the implications of the word association proposed by Peppard (2007), the use of 'vocabulary journals' is necessary for language learners to record all the new vocabularies they are studying. In this journal, learners not only write new vocabulary and meaning, but also write other words or other concepts that previously existed in their mental lexicon. With this, learners can build and strengthen the networks among words, so in the end it is expected to make it easier to remember new vocabulary.

\section{Conclusion}

The word association test as one of the methods to study the lexicon organization can explain how the storage organization of words in the mental lexicon of a language speakers, both as native and foreign speakers. From this research, it is found that the words are commonly related with other words by forming a syntagmatic relation, which is a collocation association. This is in line with the previous view that the most frequent relation in non-native speakers is a syntagmatic relation. The findings of this study provide implications for the teaching of foreign languages, especially the teaching of vocabulary. By making connections or networks among words when learning a new vocabulary, language learners can build a new network or strengthen the network of words that already been in their mental lexicon. In the end it is expected that the new vocabulary can be easy to remember and can be used in the right context. 


\section{References}

Aichison, J. 1994. Words in the Mind. Oxford: Blackwell.

Bowern, C. 2008. Linguistics Fieldwork: A Practical Guide. London: Palgrave Macmillan

Carroll, David W. 2008. Psychology of Language, 5th ed. Thomson USA: Wadsworth.

Cowles, H. Wind. 2011. Psycholinguistics 101. New York: Springer Publishing Company.

Cruse, A. 2004. Meaning in Language: An Introduction to Semantics and Pragmatics, $2^{\text {nd }}$, ed. Oxford: Oxford University Press.

Fitzpatrick, T. 2007. Word association patterns: unpacking the assumptions. International Journal of Applied Linguistics 17/3, 319-331.

Meara, P. 1982 'Word Associations in a Foreign Language: A Report on the Birkbeck Vocabulary Project.' Nottingham Linguistic Circular, 11(2): 29-37.

Menenti, Laura. 2006. 'L2-L1 Word Association in Bilinguals: Direct Evidence'. Nijmegen CNS, Vol.1.

McCarthy, M. 1990. Vocabulary. Oxford: Oxford University Press.

Peppard, J. 2007. 'Exploring the Relationship between Word-Association and Learners' Lexical Development'. Center for English Language Studies: University of Birmingham.

Riemer, N. 2005. Introducing Semantics. Cambridge: Cambridge University Press

Roux, P. W. 2013. "Words in the Mind: Exploring the relationship between word association and lexical development." Polyglossia, 24(80-91).

Schwartz, Ana I. \& Judith F. Kroll. 2006. 'Language Processing in Bilingual Speakers', in Matthew J. Traxler \& Morton A. Gernsbacher, ed.). Handbook of Psycholinguistics 2nd ed. London: Elsevier

Sheng, McGregor, and Marian 2006. 'Lexical-Semantic Organization in Bilingual Children: Evidence From a Repeated Word Association Task'. Journal of Speech, Language, and 572 Hearing Research, American Speech-Language-Hearing Association, Vol. 49, 572-587.

Steinberg, D. 2002, Introduction to Psychology of Language, Translated by Arsalan Golfam, Tehran: Samt Pub.

Wolter, B. 2002. 'Assessing Proficiency Through Word Associations: Is There Still Hope? System, Vol. 30, pp.315329. 